\title{
ANALYSIS OF THE CONTROL SYSTEM OF ELECTRIC MOTORS OF THE RUNNING GEAR OF SELF-PROPELLED MINE CARS USED IN COMPLEX MINING AND TECHNOLOGICAL CONDITIONS
}

\author{
Alim Haqberdiev ${ }^{1}$, Javokhir Toshov ${ }^{2}$ \\ ${ }^{1}$ Tashkent state technical university, Department of Mining electromechanics, University - 2, Tashkent, 100095, Uzbekistan \\ ${ }^{2}$ Tashkent state technical university, Department of Mining electromechanics, University - 2, Tashkent, 100095, Uzbekistan
}

\begin{abstract}
Annotation. This article discusses the disadvantages of electric motor control systems for the running gear of mine self-propelled cars of the $5 \mathrm{vs}-15 \mathrm{M}$ brand used for transporting ore to conveyor transport at the Tyubegatan potash Deposit and analyzes the use of a control system with a frequency Converter. Based on the results of the analysis of the recommended possible options for the electric drive, it is advisable to conduct further studies of the electric drive based on an asynchronous motor and a power circuit of a frequency converter.
\end{abstract}

\section{Introduction}

At the mines of the Tyubegatan potash Deposit (Uzbekistan), wheeled self-propelled mine wagons (SPSW) are used to deliver the rock mass beaten off by a tunneling combine to ore outlets or directly to conveyor bunkers at distances of up to 200 meters.

In difficult mining and technological conditions of the Tyubegatan potash salt Deposit, such as curvature, changes in slopes, as well as the lack of working platforms for maneuvers at the intersection of mine workings lead to some difficulties in controlling the movement of SPSW with existing relay-contactor control systems.

\section{Analysis of the Electromechanical system of the chassis of the SPSW 5BC-15M electric motor}

SPSW it is equipped with two separate travel drives that drive the right and left pair of wheels, respectively, mounted on the right and left sides of the body on the rear subframe (Fig. 1.).

Each on-Board drive SPSW brand 5VS-15M consists of a specially manufactured three-speed motor
AVT15-4/6/12 with an efficiency of $0,79 / 0,77 / 0,75$ and a slide of $8 / 14 / 13 \%$. The movement of the car is discrete, with five contactors taking into account the reverse, and has three fixed speeds forward and backward 2,5/1,6/0,8 $\mathrm{m} / \mathrm{s}$. It is possible to automatically accelerate the car to the highest speed (speed III) with the mandatory passage of reduced (I-II speeds). You can switch speeds either at a stop or while driving. At the same time, the order of speed switching is observed regardless of the driver's desire; switching in ascending order occurs only in the sequence I-II-III of speed in descending order - III-P-I, i.e. the scheme does not allow you to jump over the speed.

The existing $5 \mathrm{VS}-15 \mathrm{M}$ SPSW electric drive is based on a three-speed asynchronous electric motor with a relay-contactor control system that provides a speed range of 1:3. Shunting operations are performed at the I position of the switch, when the electric motor is running at a synchronous speed of $500 \mathrm{rpm}(0.8 \mathrm{~m} /$ s), the driver makes direct switching on and off of the engine, up to 16 times per cycle, which causes difficulties in control, additional power consumption, overheating of the motor windings and wear of contact equipment [3]. 


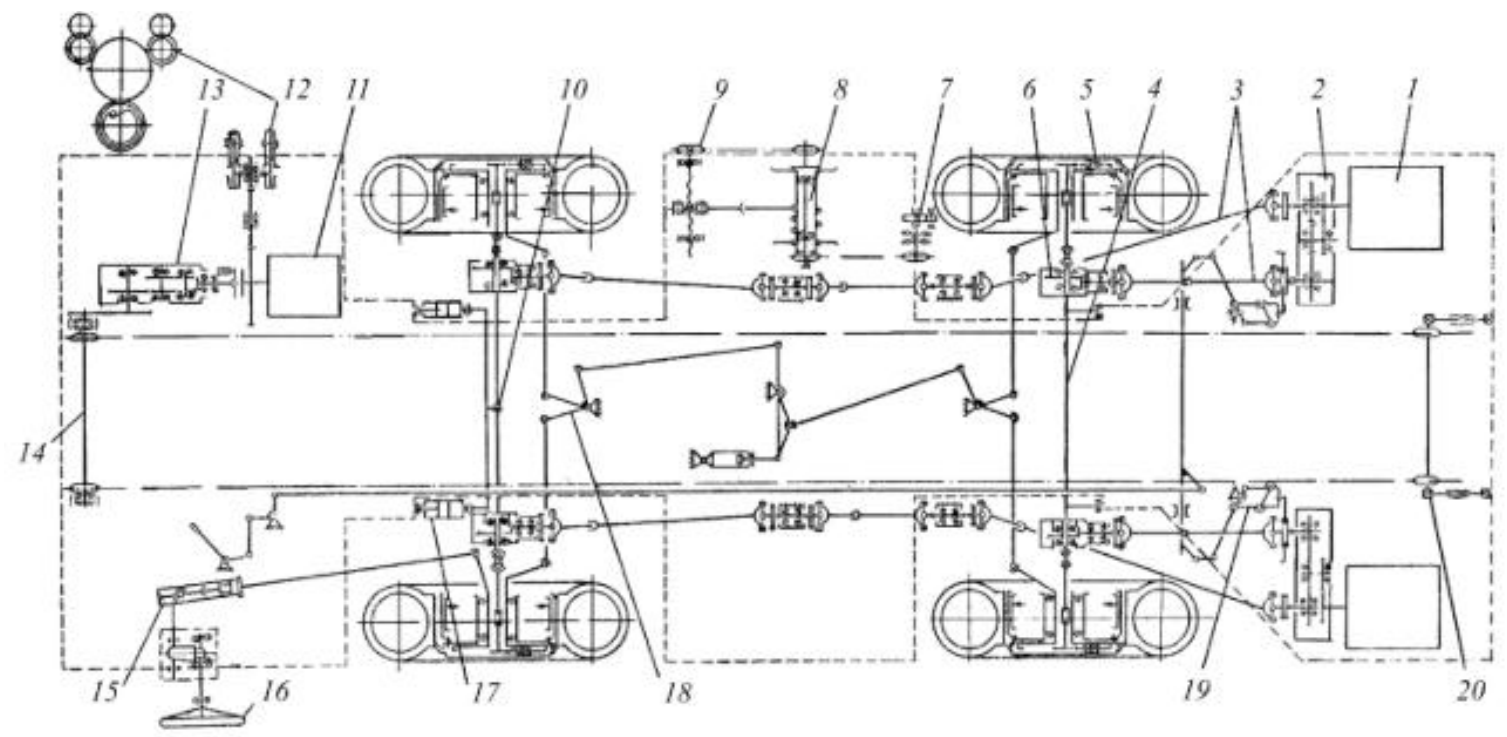

Fig.1. Kinematic diagram of a self-propelled car of the sun type with a bottom conveyor and electric drive: 1 stroke engine; 2-stroke reducer; 3-cardan gears; 4-rear axle; 5-planetary mechanism; 6-horse-drawn gearbox; 7-cable drum drive; 8-cable drum; 9-cable-laying machine; 10-front axle; 11-conveyor engine; 12-oil pumps; 13-conveyor gearbox; 14-conveyor drive shaft; 15-steering distributor; 16-steering Column; 17-hydraulic cylinders for lifting the conveyor; 18-steering; 19-Parking brake; 20-tension shaft of the conveyor.

When transporting rock mass in areas with large slopes of the path, as well as on curved sections, the application of SPSW type 5BC-15M in the conditions of the Tyubegatan potash mine negatively affects the performance of the complex (Combine-hopper loader SPSW). At the same time, on curved sections, the speed of self-propelled cars is reduced by up to 1.5 times due to insufficient maneuverability. To improve the performance of the SPSW, it is necessary to increase the speed parameters based on the selection of effective parameters and the structure of the SPSW electric drive.
It is advisable to determine the speed range for shunting operations from the condition of optimal loading of the car, the section of the face, sinking and should be from 0.05 to $0.8 \mathrm{~m} / \mathrm{s}$.

Figure 2 shows the current 5BC-15M SPSW Electromechanical system with a relay-contactor control system.

On curved sections and structural fields, the SPSW driver performs 25 to 45 turns, switches and brakes of traction engines during loading and unloading, as well as movement from the bottom to the reloading point and back over a distance.

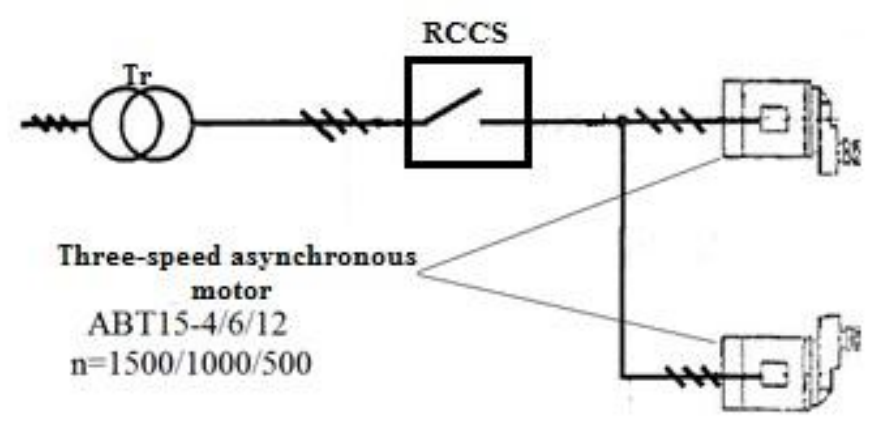

Fig. 2. The existing electromechanical system of the chassis of the SPSW electric motor of the 5VS-15M brand with a relay-contactor control system (RCCS).

Control of the electric drive, taking into account the reverse, is carried out by five contactors, which provides switching the speed of the engine running gear to $1500 / 1000 / 500 \mathrm{rpm}$.

To ensure increased efficiency, reliability and smooth operation during maneuvering operations in complex mine workings, it is necessary to exclude relay-contactor control equipment and enter a new control system with the requirement of explosion safety in the existing control stations [2].

\section{Analysis of control systems for electric motors of the chassis of modern SPSW}

Today, the introduction of an adjustable electric drive based on a frequency converter, which provides precise control of the forces and speed of rotation of the shaft of the electric drive mechanisms, is an urgent task $[4,5,6]$. 
According to the sources of literature reviews, many scientists have worked on several options for using a frequency converter and an asynchronous electric motor with a short-circuited rotor in different operating conditions of mining machines, which makes it possible to increase productivity and the most favorable operating conditions for them [4]. This system reduces wear on mechanical parts and improves the performance of the drive. The implemented traction electric drive will provide a sufficiently high accuracy (within $5 \%$ ) of maintaining the speed while simultaneously regulating the mechanical moment within large limits $[5,6]$.

Kopeysky machine-building plant has created a two-axis SPSW with a frequency-controlled drive of a self-propelled car $\mathrm{B} 17 \mathrm{~K}$ uses thyristor frequency converters of the supply voltage of traction electric motors, and the mechanisms of the stroke drives are made according to the motor-wheel scheme shown in Fig. 3

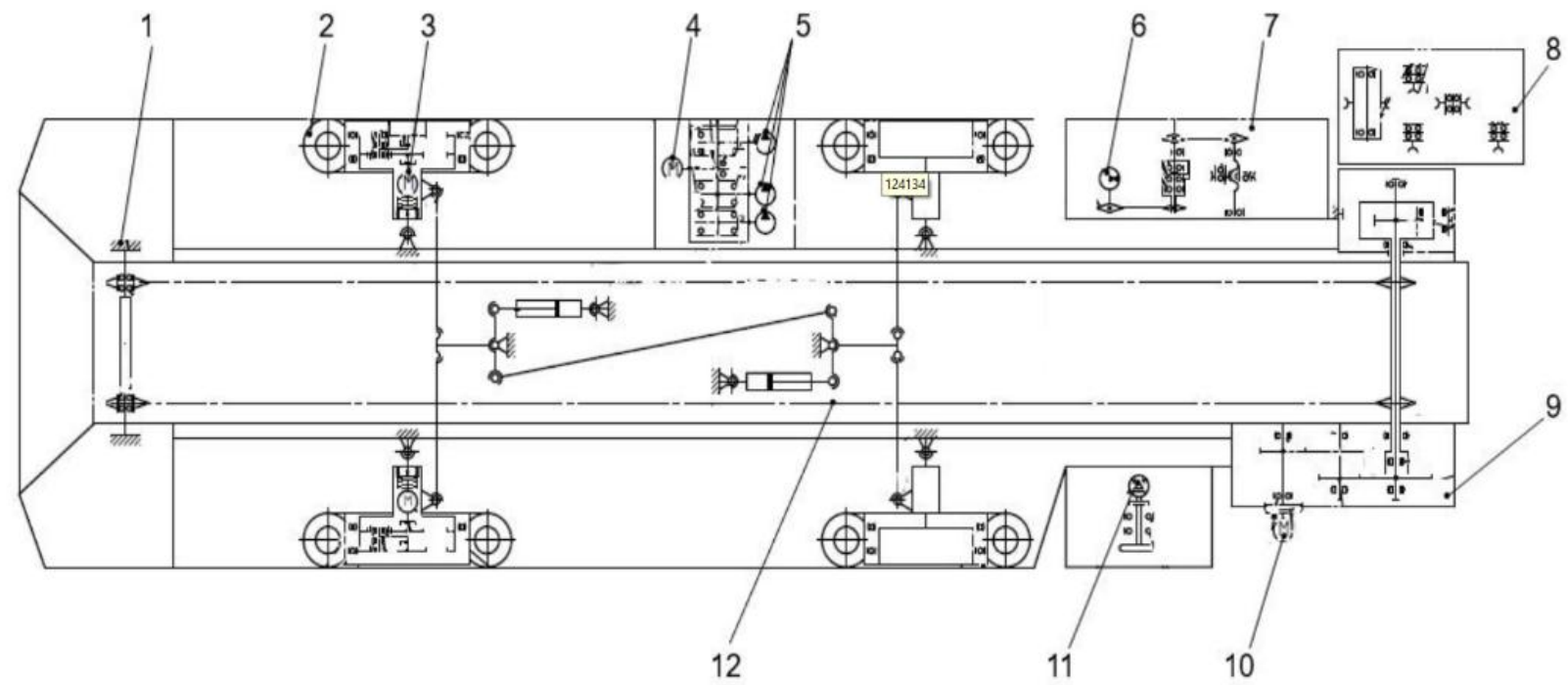

Fig.3. - The kinematic diagram of the self-propelled wagon B17K:

1 - the device is stretched; 2 - electric motor-wheel; 3 - speed motor; 4 - motor oil station; 5 - pump; 6 - motor; 7 installation of the cable reel; 8 - pin device; 9 - conveyor drive; 10 - electric motor conveyor; 11 - pump; 12 - chain scraper

Four electric motor wheels are installed on the car, which is a separate unit that structurally combines the following elements in a limited installation volume: a traction motor 3, a mechanical transmission 5, wheel without disc 1 with a tire 2 and a multi-disc brake 4 mounted on the motor shaft. A three-phase asynchronous traction motor with a short-circuited rotor, controlled by a frequency Converter, the advantages of which are the layout of the traction drives of the b17k car using a frequency Converter and motor wheels instead of complex and heavy transmission mechanisms between the electric motor and the wheel, and also significantly reduces the dynamic loads on the drive $[5,7,8]$.

The use of a frequency Converter has several advantages, as the control, locking the actuator during a crash, the fault detection motor soft start electric motors, etc.

The soft start device has a number of advantages:

- increasing the level of reliability of engine components and components of the chain of mechanical transmission elements. For example, due to the absence of sudden loads and shocks in the mechanisms of transmissions and auxiliary mechanisms, the service life of devices is increased, saving time and money that could be spent on repairs and maintenance;

- improved motor protection against network overloads, phase breaks, and power surges. This in turn prevents the motor from overheating, blocking the rotor, and unwanted short circuits;

- improved performance during engine braking and acceleration;

- reduction of starting currents to the nominal value;

ensuring reliable organization of the process control system, thanks to the built-in microcontroller and high-class control Board;

- reduce the time for repair and maintenance work by monitoring current problems and the general condition of the device on the display.

Today, the control system of the electric motor of the chassis with the use of a frequency Converter for SPSW is produced by the CIS countries, such as JSC KMZ (Kopeysk, Chelyabinsk region), LLC UK Rudgormash (Voronezh), the company Niva-holding (Mogilev, Republic of Belarus), as well as world manufacturers such as Sandvik (Austria), Joy (USA), Philips (USA) and other companies. 


\section{Application of a frequency Converter for the chassis system of the SPSW electric motor of the $5 \mathrm{vs}-15 \mathrm{M}$ brand}

Both direct and alternating current electric drives are used on self-propelled freight cars. However, due to the higher cost, weight and overall dimensions, the DC electric drive has received less use than the AC electric drive.

The AC electric drive is controlled from a relaycontactor circuit based on multi-speed motors or from static semiconductor frequency converters. Relaycontactor control systems are simple, but do not provide the required quality of electric drive control. Therefore, in the future, an electric drive with a relaycontactor control system is not relevant.

The most common technology is an $\mathrm{AC}$ conversion system that contains a DC link in its structure. The author gives an example of installing a Converter on a self-propelled freight car of the B15K type [9]. However, despite the high reliability and simplicity of this scheme, it requires the installation of a high-power brake resistor with a large volume of the cooled surface.

Given that the movement of a self-propelled car along the development with different slopes implies generator modes of engine operation, it is necessary to use an if with the possibility of energy recovery in the network. This makes it possible to reduce the weight and size parameters and increase the energy efficiency of the electric drive $[10,11]$.

Based on the results of the literature analysis of possible variants of the electric drive, it is advisable to conduct further studies of the electric drive based on an asynchronous motor and the power circuit of a frequency Converter made on the basis of a modular direct frequency Converter. With the use of a frequency Converter for the electric motor of the chassis, the 5BC-15M SPSW has the most favorable operating conditions for transporting rock mass in difficult mining and technological conditions of the Tyubegatan potash Deposit, as well as saving energy consumption, reducing engine stator overheating and wear of contact equipment.

Conclusions and recommendations:

1. It is Necessary to exclude contactor control equipment and enter a new control system for electric motors of the SPSW chassis for complex mining technological conditions.

2. To improve the technical and economic performance of the SPSW and save electric energy, it is necessary to replace the existing traction motor with a nominal slip and efficiency with an engine with better characteristics.

3. According to the analysis of possible variants of the actuator, it is expedient further research of the electric drive based on induction motor and power circuit of the frequency Converter, made on the basis of a modular direct Converter frequency.

\section{References}

1. Project. Mining complex of the Dekhkonobod potash fertilizer plant. Volume 3. Technology of mining works. Mining and mechanical part. Book 1 . Explanatory note 12.171-PZ.

2. Khakberdiev A.L. Reasons for the dismissal of selfpropelled wagons in underground mining and ways of eliminate them // Mining bulletin of Uzbekistan. -№2. 2015. p. 77-79.

3. Seregin I.N. Determination of optimal parameters of the Electromechanical system of the undercarriage of SPSW: The dissertation on competition of a scientific degree of candidate of technical Sciences. Tula. 2000.

4. Anikin A. S. Control system for a multi-motor asynchronous electric drive with frequency control of SPSW// The dissertation on competition of a scientific degree of candidate of technical Sciences. Chelyabinsk. 2011, p.152

5. Romanov V. A. Improving the efficiency of operation of SPSW of potash mines on the basis of integrated control data // The dissertation on competition of a scientific degree of candidate of technical Sciences. Perm. 2019.

6. Mikitchenko, A. Ya. Development and research of a frequency-controlled asynchronous electric drive using the direct frequency Converter system of an asynchronous motor for machines of mining enterprises // The dissertation on competition of a scientific degree of doctorate of technical Sciences. Moscow. 1999.

7. Kuleshov, A. A. Pneumatic wheel machines with onboard drives and motor wheels / - M.: mechanical engineering, 1995. - p.312.

8. Romanov V. A., Shishlyannikov D. I., Muravsky A. K., Operating experience of SPSW in the mines of the Verkhnekamskoye potash-magnesium salt Deposit // mining equipments and electromechanics. -2016 . - № 9. - p. 29-33.

9. Anikin A. S. Experience in implementing a frequency-controlled electric drive based on the VACON frequency Converter on the V15K SPSW// Proceedings of the Tula state University. Technical science. - Issue 3: at 5 p.m.-Tula: Tula publishing House, 2010. - Part 2. - P. 220-226.

10. Boroditsky E. G. Improving energy efficiency of electrically-propelled movement of the SPSW. Collection of reports of the 1st scientific year. Practice seminar with an International participation "Efficient and high-quality supply and use of electricity".

11. Azamatovich, A.N., Amrillo, M.B, Burievich, T.J., Umarxanoxich, J.R., Shavkatovich, Z.A. A complex of methods for analyzing the working fluid of a hydrostatic power plant for hydraulic mining machines /nternational Journal of Advanced Science and Technology. Volume 29, Issue 5 Special Issue, 28 March 2020, Pages 852-855 